\title{
Acid modified carbon coated monolith for methyl orange adsorption
}

\begin{abstract}
Carbon coated monolith (CCM) was chemically modified by treating with nitric acid. The acid modified carbon coated monolith (ACCM) was then characterized by using various techniques. Two folds increase in acidic sites was observed on ACCM compared to CCM. Surface studies showed mesoporous nature of ACCM. A decrease in ACCM surface area and an increase in pore volume observed after the modification. The ATR-FT-IR studies showed increase in carboxylic groups on ACCM confirming CCM oxidation by nitric acid. The $\mathrm{pH}$ studies showed optimum adsorption $(88 \mathrm{mg} / \mathrm{g})$ at $\mathrm{pH} 6$ which is very near to pHPZC of ACCM. Contact time studies showed equilibration time in between 4320 and 4560 min for initial MO concentration range $0.05-0.6 \mathrm{~g} / \mathrm{L}$. Comparatively $53 \%$ higher $\mathrm{MO}$ adsorption was observed on ACCM than CCM under similar experimental conditions. Freundlich model applicability confirms multilayer MO adsorption on ACCM surface. Pseudo-second-order kinetics model was fitted best to the experimental data revealing chemical nature of adsorption process. The adsorption process is endothermic and spontaneous in nature. Desorption studies showed optimum MO recovery (73\%) when $1 \mathrm{~N} \mathrm{NaOH}$ was used as an eluent.
\end{abstract}

Keyword: Methyl orange; Acid modified carbon coated monolith; Adsorption; Desorption; Thermodynamics 